\title{
Associations between Dietary Intake of Fruits and Vegetables in Relation to Urinary Estrogen DNA Adduct Ratio
}

\author{
Kerryn W. Reding1,2*, Muhammad Zahid ${ }^{3}$, Ercole Cavalieri ${ }^{3}$, Eleanor G. Rogan ${ }^{3}$, \\ Brianne S. Raccor ${ }^{1}$, Charlotte Atkinson ${ }^{4}$, Mellissa Yong5, Katherine M. Newton' \\ Johanna W. Lampe ${ }^{1,2}$ \\ ${ }^{1}$ University of Washington, Seattle, USA \\ ${ }^{2}$ Fred Hutchinson Cancer Research Center, Seattle, USA \\ ${ }^{3}$ University of Nebraska Medical Center, Omaha, USA \\ ${ }^{4}$ University of Bristol, Bristol, UK \\ ${ }^{5}$ Merck \& Co., Inc., North Wales, USA \\ ${ }^{6}$ Group Health Research Institute, Seattle, USA \\ Email: kreding@uw.edu
}

Received 12 April 2014; revised 13 May 2014; accepted 4 June 2014

Copyright (C) 2014 by authors and Scientific Research Publishing Inc.

This work is licensed under the Creative Commons Attribution International License (CC BY).

http://creativecommons.org/licenses/by/4.0/

(c) (i) Open Access

\section{Abstract}

Background: Estrogen exposure plays a role in breast cancer (BC) development. A novel estrogen biomarker, the estrogen DNA adduct (EDA) ratio, was shown to be elevated in women at high-risk of $B C$ and among BC cases. Modifiable factors may impact the EDA ratio, with studies demonstrating that resveratrol reduces EDA ratio in vitro. We sought to examine the hypothesis that dietary intake of fruits and vegetables is inversely associated with EDA ratio. Methods: This analysis was conducted in 53 pre-menopausal, healthy women aged 40 - 45 years from a cross-sectional study in which participants provided first-void urine samples and 3-day food records. Urine samples were analyzed using ultra performance liquid chromatography/tandem mass spectrometry. The EDA ratio was calculated as the estrogen-DNA adducts divided by estrogen metabolites and conjugates. A trend test was used to assess associations between tertiles of dietary intake using linear regression. Results: After adjustment for age, total energy, percent adiposity, serum estradiol and estrone-sulfate, we observed inverse associations of EDA ratio with carbohydrate consumption ( $P$ $=0.01)$ and vegetable intake $(P=0.01)$. EDA ratio was inversely associated with 5 botanical groups (Chenopodiaceae: $P=0.02$; Umbelliferae: $P=0.03$; Compositae: $P=0.01$; Ericaceae: $P=0.01$; Musaceae: $P=0.03$ ) but not fruit intake overall. Conclusion: Although these data require replication before conclusions are drawn, this report suggests an inverse association between vegetable and carbohydrate consumption and EDA ratio. Impact: While more information is still needed, these *Denotes shared first authorship. 
findings suggest a link between dietary intake and a biomarker that is both associated with highrisk BC status and associated with modifiable factors.

\title{
Keywords
}

\author{
Breast Cancer, Nutritional Assessment, Biomarker, Estrogens
}

\section{Introduction}

Estrogen exposure has been implicated in breast cancer (BC) development [1]. While much of the focus has been upon estrogen's proliferative effects, more recently research has focused on estrogen's genotoxic effects [2] [3]. Estrogen metabolites within the catechol estrogen (CE) pathway have been investigated for their role in BC due to their ability to form adducts within DNA [4]-[6]. Cavalieri et al. developed an assay to measure the estrogen DNA adduct (EDA) ratio, which consists of EDAs in relation to their unbound counterparts (estrogen metabolites and conjugates) [3]. Three studies reported elevated EDA ratios among BC cases and high-risk women compared to women at average-risk of BC (defined by Gail score; $P<0.001$ ) [7]-[9].

EDAs are thought to play a role in BC initiation due to their role in forming depurinating DNA adducts, which have been described in a number of studies [4]-[6]. In general, estrone and estradiol $\left(E_{1} / E_{2}\right)$ are converted into CEs by cytochrome P450 (CYP) enzymes. The CEs, unless inactivated, are oxidized into CE quinones. These quinones are capable of reacting with DNA to form depurinating adducts, which result in apurinic sites and require DNA repair to resolve the missing base pair. Greater adduct formation with the 4-CE compared to the 2CE has been observed, likely as a result of the location of the hydroxy group [6]. Within this pathway, enzymes are involved in both activating and inactivating CE metabolites [3] [10]. For example, CYP1A1 and CYP1B1 convert $E_{1} / E_{2}$ to the 2- and 4-CE, respectively; while Phase II enzymes, including catechol-O-methyltransferase (COMT), glutathione $\mathrm{S}$ transferase (GST), UDP-glucuronosyltransferase (UGT), sulfotransferase (SULT), and NADPH-quinone reductase (NQ01), can inactivate CEs. Thus, there is biological plausibility for a role of EDAs in BC development as well as indication that this pathway involves a number of enzymes.

Interestingly, many of the enzymes in the CE pathway are modulated by components of diet. Several classes of phytochemicals have been shown to influence the activity of phase II enzymes, including UGT, GST, NQ01, and SULT enzymes. For example, flavones (such as those found in the Umbelliferae botanical grouping) decrease CYP1A1 activity while inducing UGT activity [11]. Although the relationship between dietary constituents and phase II enzymes is complex, the overall direction of phytochemicals, such as flavones, on phase II enzymes is consistent with chemoprevention. Thus, the intake of foods rich in certain phytochemicals (e.g., flavones), may influence the CE pathway due to their induction of enzymes involved in estrogen metabolism [12][14].

Additional studies indicate that the EDA ratio can be modulated by dietary components, with evidence coming predominantly through in vitro studies [3] [15]. Such studies have shown that resveratrol (a dietary polyphenol) and N-acetylcysteine (NAcCys, a dietary supplement) when administered to immortalized/non-transformed cell lines can substantially reduce EDA ratios and cell transformation [14] [16] [17]. Within a pilot study of healthy adults, Cavalieri et al. observed reduced EDA concentrations after 1 month use of NAcCys [3]. Taken together, these studies suggest that dietary consumption of phytochemicals may influence the EDA ratio; however, no studies have investigated the association between usual dietary consumption and the EDA ratio. Given the proposed effect of phytochemicals on the EDA ratio, we hypothesized that intake of fruits and vegetables, such as umbelliferae vegetables, would be inversely associated with the EDA ratioin women.

\section{Materials and Methods}

\subsection{Study Population}

This analysis was conducted within a randomly selected subset of 117 premenopausal women (out of 203, due to funding constraints) who participated in the Equol, Breast, and Bone (EBB) study, a cross-sectional study originally designed to investigate equol production, hormones, and breast density in premenopausal women. 
Study methods have been previously described [18]. Briefly, women were recruited from the Group Health Cooperative (GHC) in western Washington State. Eligible women were premenopausal, aged 40 to 45 years, and had received a screening mammogram at GHC. Ineligible women were current or recent users of hormone therapy/oral contraceptives or antibiotics, had a history of BC, or had shown signs of perimenopause.

After obtaining informed consent, EBB participants: completed a health and demographics questionnaire; provided a blood sample and a spot urine sample (collected at a clinic visit scheduled between days 5 - 9 of their menstrual cycle); underwent a Dual X-ray Absorptiometry (DXA) scan; and completed a 3-day food record (3DFR) within two weeks of urine collection. Dietary intake data from the 3-DFR were analyzed using the Nutrition Data System for Research software using previously described methods [18]. Estimates of daily intake of nutrients, grains, meats and shellfish, egg, dairy, tea and coffee, as well as botanically-defined groupings of fruits and vegetables were obtained [19]. This study was approved by the Institutional Review Boards at GHC and the Fred Hutchinson Cancer Research Center.

\subsection{Urinary Estrogen Metabolites}

Urine samples were processed with the addition of ascorbic acid, and stored at $-80^{\circ} \mathrm{C}$. Laboratory methods on the urinary EDA ratio have been previously published [7] [8]. In order to concentrate and partially purify the estrogen metabolites and DNA adducts, $2 \mathrm{~mL}$ of urine (pH adjusted to 7) was placed on a $1 \mathrm{~mL}$ solid phase extraction cartridge (SPE; Phenyl Bond Elut, $100 \mathrm{mg}$, Varian, Palo Alto, CA) preconditioned with methanol, water, and $10 \mathrm{mM}$ ammonium formate $(\mathrm{pH} 7)$. The sample was loaded onto the SPE cartridge, washed, eluted, and concentrated; was reconstituted in methanol:water (1:1); and ultraperformance liquid chromatography/tandem mass spectrometry (UPLC/MS-MS) was used to separate and analyze the 32 estrogen metabolites and DNA adducts in urine. The sample was injected onto an Acquity UPLC BEH C18 column $(1 \times 100 \mathrm{~mm}, 1.7 \mu \mathrm{m})$ using a flow rate of $0.15 \mathrm{~mL} / \mathrm{min}$. The total run time was $10 \mathrm{~min}$ and the mobile phase consisted of $0.1 \%$ formic acid in water (A) and $0.1 \%$ formic acid in acetonitrile (B). A gradient was used over the course of the run to obtain separation. The linear gradient gradually increased from $20 \%$ B to $21 \%$ over 4 min and then further increased to $55 \%$ B over 6 min. Analytes were detected using electron spray ionization (ESI) in positive and negative ion modes on a Waters (Milford, MA) Quattro Micro triple quadruple mass spectrometer. Multiple reaction monitoring was used to monitor all compounds and optimization of cone voltages and collision energies were obtained by direct infusion of standard compounds onto the instrument. The instrument was operated using Micromass Mass Lynx 4.1 software (Waters) and data were processed used QuanLynx. The limit of detection for the 32 analytes was determined by spiking charcoal stripped urine with known amounts of standard compounds and ranged from 1.2 - $867 \mathrm{fmol}$ on column [8]. 10\% blinded quality controls were included across 6 batches. The intra-batch coefficient of variation (CV) for the calculated EDA ratio ranged from $2.7 \%$ to $67.0 \%$. Only batches that had less than $15 \%$ intra-batch CV ( $\mathrm{n}=53$ samples) were retained for use in the statistical analysis presented here ( $\mathrm{n}=3$ batches). The \%CV for these three batches was $12.4 \%, 8.9 \%$, and $2.7 \%$ (mean\% CV = $8.0 \pm 4.9$ ).

\subsection{Statistical Analysis}

This statistical analysis was conducted in 53 women whose samples were analyzed within the three batches with $<15 \%$ intra-batch CV. The numerator of the EDA ratio contains depurinated estrogen-DNA adducts; the denominator contains the estrogen metabolites and conjugates; summed for the 2- and 4-CEs separately as described previously [7] [8].

Lack of normality was assessed for each continuous variable; the distribution was skewed for the EDA ratio and many dietary factors. As a result, the EDA ratio was log-transformed. Tertiles were created for the dietary factors, with the exception of the botanical groupings. For botanical groupings, analyses were limited to those groups that were consumed by at least $15 \%$ of participants. Within those remaining botanical groupings, intake was categorized as any intake versus none.

We tested associations between the EDA ratio and dietary factors using generalized linear models (GLM) adjusted for potential confounding factors. A confounding factor was included in the GLM if it was associated with the EDA ratio (at $\alpha=0.05$ determined using one-way ANOVA) and with dietary factors. All models included confounding factors (i.e., percent adiposity, serum estradiol and estrone-sulfate $\left[\mathrm{E}_{1} \mathrm{~S}\right]$ ), in addition to age and total energy intake. A trend test was used to assess associations between tertiles of dietary intake and the EDA ratio. Correlations were also examined between continuous variables to ensure that variables with high 
correlations were not included in the model together. Because these hypotheses were specified a priori we did not adjust for multiple comparisons. Analyses were conducted using Stata v. 11.

\section{Results}

Our study population consisted of healthy, premenopausal women with an average age of 42.5 years and BMI of $25.6 \mathrm{~kg} / \mathrm{m}^{2}$ (Table 1). Our population was predominantly White women (81.1\%), never smokers (53.6\%), and relatively high socioeconomic status $(94.3 \%$ attended $\geq$ some college). Among this group of premenopausal women, the EDA ratio values ranged from 4.1 to 99.4 [mean = 22.23 (SD16.09)].

An elevated EDA ratio was associated with low total carbohydrate consumption $(P=0.01)$, low vegetable intake $(P=0.01)$, low fruit and vegetable intake $(P=0.03)$, high fish and shellfish consumption $(P=0.03)$, and high egg consumption $(P=0.03)$ after adjustment for age, total energy intake, percent adiposity, serum $E_{2}$ and $\mathrm{E}_{1} \mathrm{~S}$ (Table 2). Based on these findings [i.e., opposite directions in the associations for botanical groupings and protein-based groups (eggs, fish and shellfish)], we further examined the association between the percent of energy consumed from macronutrients. The percent of energy from carbohydrate was associated with the EDA ratio [coefficient $=-0.27$ (SE 0.12); $P=0.03$ ], but the percent of energy from protein $(P=0.53$ ), and the percent of energy from fat $(P=0.16)$ were not (data not shown).

\section{Table 1. Demographic characteristics of the study participants.}

\begin{tabular}{|c|c|c|}
\hline \multirow[t]{2}{*}{ Characteristic } & \multicolumn{2}{|c|}{$\mathrm{n}=53$} \\
\hline & Mean & SD \\
\hline Age, years & 42.5 & 1.3 \\
\hline BMI, $\mathrm{kg} / \mathrm{m}^{2}$ & 25.6 & 4.5 \\
\hline Height, cm & 164.7 & 7.1 \\
\hline Weight, kg & 69.5 & 12.6 \\
\hline Waist: Hip ratio & 0.79 & 0.06 \\
\hline \multirow[t]{2}{*}{ Percent adiposity } & 31.9 & 6.9 \\
\hline & $\mathbf{n}$ & $\%$ \\
\hline Parous & 39 & 73.6 \\
\hline Had a history of breast-feeding & 32 & 64.0 \\
\hline Had a history of OC or HT use & 38 & 71.7 \\
\hline First degree relative with breast and/or ovarian cancer & 7 & 30.4 \\
\hline \multicolumn{3}{|l|}{ Smoking status } \\
\hline Current & 16 & 30.2 \\
\hline Never & 37 & 69.8 \\
\hline \multicolumn{3}{|l|}{ Race/ethnicity } \\
\hline Asian & 6 & 11.3 \\
\hline White & 43 & 81.1 \\
\hline Other & 4 & 7.6 \\
\hline \multicolumn{3}{|l|}{ Years of school completed } \\
\hline$\leq 12$ & 3 & 5.7 \\
\hline $13-15$ & 19 & 35.8 \\
\hline 16 & 13 & 24.5 \\
\hline$\geq 17$ & 18 & 34.0 \\
\hline \multicolumn{3}{|l|}{ Income } \\
\hline$\leq \$ 49,999$ & 10 & 18.9 \\
\hline$\$ 50,000-\$ 75,000$ & 13 & 24.5 \\
\hline$>\$ 75,000$ & 23 & 43.4 \\
\hline Prefer not to answer & 7 & 13.2 \\
\hline
\end{tabular}


Table 2. Associations of nutrients and food groups with the Estrogen DNA Adduct Ratio.

\begin{tabular}{|c|c|c|c|c|c|}
\hline & \multicolumn{3}{|c|}{ Estrogen DNA Adduct Ratio $^{1}$} & \multirow[b]{2}{*}{ Coefficient (SE) $)^{2}$} & \multirow[b]{2}{*}{$P$-value } \\
\hline & T1 (95\% CI) & T2 (95\% CI) & T3 (95\% CI) & & \\
\hline \multicolumn{6}{|l|}{ Nutrients } \\
\hline Energy & $17.5(9.2-25.7)$ & $19.8(13.8-25.8)$ & $27.3(19.6-34.9)$ & $0.02(0.10)$ & 0.85 \\
\hline Tertilecutpoints (kcal/d) & $<1686$ & $1820-2069$ & $2070-3183$ & & \\
\hline Fat & 18.9 (10.7 - 27.1) & $25.8(18.8-32.8)$ & $21.3(10.9-31.7)$ & $0.17(0.18)$ & 0.33 \\
\hline Tertilecutpoints (g/d) & $<64.2$ & $67.5-85.5$ & $86.4-148.3$ & & \\
\hline Carbohydrate & 19.7 (14.9 - 24.5) & $19.0(15.6-22.5)$ & $19.9(15.5$ - 24.3) & $-0.52(0.18)$ & 0.01 \\
\hline Tertilecutpoints (g/d) & $<185.3$ & $190.6-250.9$ & $255.0-378.5$ & & \\
\hline Total sugars & $20.3(10.6-30.0)$ & $15.6(8.6$ - 22.6) & $29.3(21.2-37.4)$ & $-0.26(0.16)$ & 0.11 \\
\hline Tertilecutpoints (g/d) & $<75.7$ & $78.1-114.0$ & $116.4-202.9$ & & \\
\hline Protein & $13.6(5.0-22.1)$ & $25.2(19.2-31.1)$ & $27.3(18.7-35.9)$ & $0.18(0.17)$ & 0.27 \\
\hline Tertilecutpoints (g/d) & $<68.0$ & $70.0-88.8$ & $89.0-132.8$ & & \\
\hline Total dietary fiber & $21.6(13.0-30.2)$ & $20.2(14.1-26.4)$ & $23.7(16.4-31.1)$ & $-0.22(0.15)$ & 0.14 \\
\hline Tertilecutpoints (g/d) & $<14.2$ & $14.5-19.5$ & $19.7-49.4$ & & \\
\hline Caffeine & $24.3(16.3-32.4)$ & $19.1(13.4-25.5)$ & $21.8(13.1-30.5)$ & $0.07(0.13)$ & 0.64 \\
\hline Tertilecutpoints (mg/d) & $<71.1$ & $75.8-193.4$ & $196.5-570.7$ & & \\
\hline Alcohol & $24.7(17.3-32.2)$ & $24.3(16.2-32.5)$ & $19.0(11.5-26.5)$ & $-0.10(0.11)$ & 0.36 \\
\hline Tertilecutpoints (g/d) & 0 & $0.01-0.3$ & $0.5-39.9$ & & \\
\hline \multicolumn{6}{|c|}{ Food Groups (servings/d) } \\
\hline Fruit and vegetable & $25.3(17.6$ - 32.9) & $20.8(14.5-27.0)$ & $20.8(14.7-26.9)$ & $-0.28(0.13)$ & 0.03 \\
\hline Tertilecutpoints & $<3.7$ & $3.8-5.6$ & $5.7-11.7$ & & \\
\hline Fruit & $19.6(11.0$ - 28.1) & $23.1(15.6$ - 30.6) & $23.5(15.9-31.0)$ & $-0.13(0.14)$ & 0.35 \\
\hline Tertilecutpoints & $<0.93$ & $0.94-2.1$ & $2.2-7.1$ & & \\
\hline Vegetables & $25.6(18.3-32.9)$ & $23.7(18.4$ - 28.9) & $17.9(10.8-24.9)$ & $-0.27(0.10)$ & 0.01 \\
\hline Tertilecutpoints & $<2.35$ & $2.36-3.60$ & $3.62-6.60$ & & \\
\hline Grains, refined & $14.9(6.3-23.5)$ & $25.9(19.4-32.5)$ & $25.1(16.6-33.8)$ & $0.14(0.11)$ & 0.22 \\
\hline Tertilecutpoints & $\leq 3.2$ & $3.21-4.7$ & $5.1-12.6$ & & \\
\hline Grains, whole & $20.2(10.7-29.7)$ & $18.3(11.7-24.9)$ & $26.2(18.5$ - 33.9) & $-0.10(0.15)$ & 0.49 \\
\hline Tertilecutpoints & $<0.64$ & $0.64-1.8$ & $1.9-5.6$ & & \\
\hline Meat and poultry & $17.3(9.3-25.3)$ & $20.1(14.2-26.1)$ & $35.5(25.3-45.6)$ & $0.21(0.14)$ & 0.13 \\
\hline Tertilecutpoints & $<3.6$ & $3.6-5.95$ & $6.0-14.9$ & & \\
\hline Fish and shellfish & $16.4(9.4-23.4)$ & $20.7(13.9-27.5)$ & $30.5(22.4-38.6)$ & $0.23(0.10)$ & 0.03 \\
\hline Tertilecutpoints & 0 & $0-0.49$ & $0.5-6.0$ & & \\
\hline Eggs & $19.6(10.8$ - 28.4) & $22.5(16.6$ - 28.4) & $23.9(15.5-32.4)$ & $0.30(0.13)$ & 0.03 \\
\hline Tertilecutpoints & $<0.2$ & $0.2-0.53$ & $0.59-2.6$ & & \\
\hline Dairy foods & $25.2(16.6$ - 33.9) & $21.1(14.8-27.5)$ & $20.2(11.9-28.4)$ & $-0.05(0.14)$ & 0.72 \\
\hline Tertilecutpoints & $<1.42$ & $1.42-2.55$ & $2.59-6.00$ & & \\
\hline Tea and coffee & $21.7(13.5$ - 29.9) & $24.0(18.2-29.7)$ & $20.3(11.4-29.3)$ & $0.07(0.13)$ & 0.60 \\
\hline Tertilecutpoints & $<0.7$ & $0.7-2.5$ & $2.6-8.4$ & & \\
\hline
\end{tabular}

1). For the ratio: $\left[4-\mathrm{OHE}_{2}\left(\mathrm{E}_{1}\right)-1-\mathrm{N} 7 \mathrm{Gua}+4-\mathrm{OHE}_{2}\left(\mathrm{E}_{1}\right)-1-\mathrm{N} 3 \mathrm{Ade}\right]$ in numerator, and [4-OHE $\mathrm{O}_{2}\left(\mathrm{E}_{1}\right)+4-\mathrm{OCH}_{3} \mathrm{E}_{2}\left(\mathrm{E}_{1}\right)+4-\mathrm{OHE}_{2}\left(\mathrm{E}_{1}\right)-2-\mathrm{Cys}+4-\mathrm{OHE}_{2}$ $\left(\mathrm{E}_{1}\right)-2-\mathrm{SG}+4-\mathrm{OHE} 2(\mathrm{E} 1)$ 2-NAcCys] in denominator; added to [2-OHE $\left.\mathrm{E}_{2}\left(\mathrm{E}_{1}\right)-6-\mathrm{N} 3 \mathrm{Ade}\right]$ in numerator, and [2-OHE $\left(\mathrm{E}_{1}\right), 2-\mathrm{OCH}_{3} \mathrm{E}_{2}\left(\mathrm{E}_{1}\right)+2-\mathrm{OH}-3-$ $\mathrm{OCH}_{3} \mathrm{E}_{2}\left(\mathrm{E}_{1}\right)+2-\mathrm{OHE}_{2}-(1,4)-\mathrm{Cys}, 2-\mathrm{OHE}_{1}-1-\mathrm{Cys}+2-\mathrm{OHE}_{1}-4-\mathrm{Cys}+2-\mathrm{OHE}_{2}\left(\mathrm{E}_{1}\right)-1-\mathrm{NAcCys}+2-\mathrm{OHE}_{2}\left(\mathrm{E}_{1}\right)-4-\mathrm{NAcCys}+2-\mathrm{OHE} \mathrm{E}_{2}\left(\mathrm{E}_{1}\right)-1-\mathrm{SG}_{+}+$ $\left.2-\mathrm{OHE}_{2}\left(\mathrm{E}_{1}\right)-4-\mathrm{SG}\right]$ in denominator; 2 ) adjustment for age, total energy, percent adiposity, serum estradiol and Estrone; 3 ) $P$-value for trend test across the tertiles. T1: tertile 1; T2: tertile 2; T3: tertile 3. 
To follow up on the inverse association observed between total fruit and vegetable intake and the EDA ratio, we investigated associations with botanical groups. We observed that the EDA ratio was associated with five botanical groupings (Table 3). Among the vegetable-based botanical groups, elevated EDA ratio was associated with low Chenopodiaceae consumption (e.g., spinach and beets; $P=0.02$ ), low Umbelliferae consumption (e.g., carrots and celery; $P=0.03$ ), low Compositae consumption (e.g. lettuce; $P=0.01$ ) and borderline association with low Cruciferae consumption (e.g. broccoli and cabbages; $P=0.05$ ). With respect to fruit-based botanical groupings, elevated EDA ratio was associated with low Ericaceae consumption (e.g. blueberries and cranberries; $P=0.01$ ) and low Musaceae consumption (e.g. bananas; $P=0.03$ ).

\section{Discussion}

We observed inverse associations between reported dietary intake of botanical groups and the EDA ratio, as well as positive associations between the EDA ratio andfish/shellfish and eggs. We had hypothesized an inverse relationship for EDA with fruit and vegetable consumption but had not hypothesized there to be an association between EDA and fish/shellfish and eggs. To our knowledge, we are the first research group to investigate associations between dietary intake and the EDA ratio.

Table 3. Association between Estrogen DNA Adduct Ratio and fruit and vegetable botanical groups.

\begin{tabular}{|c|c|c|c|c|c|c|c|c|}
\hline \multirow{3}{*}{$\begin{array}{l}\text { Botanical } \\
\text { groupings }\end{array}$} & \multirow{3}{*}{$\begin{array}{l}\text { Common } \\
\text { example }^{3,4}\end{array}$} & \multicolumn{7}{|c|}{ Consumption } \\
\hline & & \multicolumn{2}{|c|}{ None } & \multicolumn{3}{|c|}{ Any } & \multirow[b]{2}{*}{ Coefficient (SE) } & \multirow[b]{2}{*}{$P$-value ${ }^{1}$} \\
\hline & & n (\%) & EDA ratio & n (\%) & $\begin{array}{c}\text { Median } \\
\text { consumption }\end{array}$ & EDA ratio & & \\
\hline \multicolumn{9}{|l|}{ Vegetables } \\
\hline Gramineae & Corn & $41(78.8)$ & 22.7 & $11(21.2)$ & 0.07 & 20.1 & $0.19(0.27)$ & 0.47 \\
\hline Oleaceae & Olive & 37 (71.2) & 23.5 & $15(28.8)$ & 0.08 & 18.9 & $-0.27(0.21)$ & 0.19 \\
\hline Lauraceae & Avocado & 35 (67.3) & 21.9 & 17 (32.7) & 0.08 & 22.6 & $-0.12(0.23)$ & 0.60 \\
\hline Agaricaceae & Mushroom & 33 (63.5) & 23.2 & $19(36.5)$ & 0.04 & 20.3 & $-0.01(0.22)$ & 0.98 \\
\hline Chenopodiaceae & Spinach & 32 (61.5) & 24.0 & $20(38.5)$ & 0.15 & 19.2 & $-0.47(0.20)$ & 0.02 \\
\hline Umbelliferae & Carrots, celery & 18 (34.6) & 27.6 & $34(65.4)$ & 0.27 & 19.3 & $-0.40(0.18)$ & 0.03 \\
\hline Cruciferae & Broccoli & $16(30.8)$ & 27.4 & $36(69.2)$ & 0.20 & 19.8 & $-0.40(0.20)$ & 0.05 \\
\hline Compositae & Lettuce & $11(21.2)$ & 28.0 & $41(78.8)$ & 0.37 & 20.6 & $-0.63(0.22)$ & 0.01 \\
\hline Leguminosae & Alfalfa & $6(11.5)$ & 35.8 & 46 (88.5) & 0.64 & 20.4 & $-0.18(0.14)$ & 0.19 \\
\hline Solanaceae & Potato & $3(5.8)$ & 17.6 & 49 (94.2) & 0.80 & 22.4 & $-0.01(0.22)$ & 0.96 \\
\hline Liliaceae & Onions & $3(5.8)$ & 17.7 & 49 (94.2) & 0.18 & 22.4 & $0.68(0.57)$ & 0.23 \\
\hline \multicolumn{9}{|l|}{ Fruit } \\
\hline Ericaceae & Blueberries & $41(78.8)$ & 21.6 & $11(21.2)$ & 0.20 & 24.1 & $-0.70(0.28)$ & 0.01 \\
\hline Vitaceae & Grapes & 38 (73.1) & 21.5 & 14 (26.9) & 0.18 & 23.8 & $-0.23(0.22)$ & 0.30 \\
\hline Musaceae & Banana & 27 (51.9) & 24.7 & 25 (48.1) & 0.50 & 19.4 & $-0.41(0.18)$ & 0.03 \\
\hline Curcurbitaceae & Melon & $22(42.3)$ & 18.6 & $30(57.7)$ & 0.16 & 24.8 & $0.06(0.21)$ & 0.76 \\
\hline Rutaceae & Citrus fruits & 17 (32.7) & 22.8 & 35 (67.3) & 0.50 & 21.9 & $0.37(0.21)$ & 0.07 \\
\hline Rosaceae & Apple & $5(9.6)$ & 28.0 & 47 (90.4) & 0.50 & 21.5 & $0.15(0.40)$ & 0.71 \\
\hline
\end{tabular}

1) Testing association with the EDA ratio of any versus no consumption, adjusted for age, total calories, percent carbohydrate intake, percent adiposity, serum estradiol and estrone sulfate; 2) Median level among those consuming food categorized within this botanical grouping in servings per day; 3 ) Limited to botanical groupings that is consumed by $\geq 15 \%$ of study population; 4$)$ Lauraceae: Avocado, cinnamon; Chenopodiaceae: Silver beet, spinach, beetroot, beets; Cruciferae: broccoli, brussels sprouts, cabbages, cauliflower, collard greens, daikon, horseradish, kale, kohlrabi, mustard greens and seeds, radishes, arugula, rutabagas, turnips, watercress; Solanaceae: potato, tomato, chili, tomatillo, eggplant, tamarillo; Leguminosae: alfalfa, jicama, lentils, licorice, fava, pinto, garbanzo, kidney, lima, pinto, and soy beans; Umbelliferae: carrots, celery, celeriac, parsley, dill; Compositae: artichokes, chamomile, dandelions, echinacea, endive; Liliaceae: chives, garlic, leeks, onions, scallions, asparagus; Gramineae: corn, lemongrass, sugar cane, oats, barley; Oleaceae: olive; Agaricaceae: cultivated button mushroom; Curcurbitaceae: melon, watermelon, cucumber, courgette, marrow pumpkin, squash, balsam-pear; Ericaceae: blueberries, cranberries, huckleberries, lingonberries, oheloberries, wintergreen; Rosaceae: almond, apple, pear, strawberry, raspberry, apricot, plum, peach, blackberry, cherry, Juneberry, loganberry, nectarine, prune, quince, salmonberry, acerola, loquat; Rutaceae: oranges, mandarin, grapefruit, kumquats, lemons, limes, tangerines; Vitaceae: grapes; Musaceae: banana, plantain. 
Our findings of an inverse association between EDA and botanical groups are supported by several lines of research. This includes: 1) reports of phytochemicals inducing enzymes which inactivate CEs, rendering them more easily excreted [12]-[14] [17] [20], including induction of GST enzymes by anthocyanidins (a flavonoid contained in plant-based foods, including berries, beets, bananas) [21] [22]; 2) inhibition of CE-activating enzyme, CYP1B1, by resveratrol as demonstrated in MCF-10F cells [16] and by berry supplementation in animal models [20]; and 3) phytochemicals, including resveratrol, inducing UGT activity [23]. Past studies have also reported on inverse associations between estrogen metabolites and fruit and vegetable intake in population-based studies [16] [24]-[27]. Overall, our findings are in general agreement with prior experimental work in this research area showing that resveratrol and NAcCy scan inhibit both the formation of CE quinones and their reaction with DNA in cultured cells [14] [16] [17].

NAcCys, a potent antioxidant, can block quinone induced oxidative DNA damage through three primary mechanisms [28]. First, it can covalently bind with CE quinone to form an inactive quinone conjugate (4-OHE $2-2-$ NAcCys). Second, it may act as a quencher of CE semiquinones (CE-SQ) that are generated during redox cycling between CE and quinones [28] [29]. Lastly and more importantly, through a biosynthesis pathway it can be transformed to cysteine, which could elevate the levels of cellular glutathione and produce a new NAcCys [30]. Resveratrol (3, 5, 4'-hydroxystilbene), present in grapes and other plants, has several anti-carcinogenic properties [31]. Resveratrol's anticarcinogenic effect within the estrogen pathway is exhibited through the following three mechanisms. One is the induction of key protective enzymes (e.g. NQ01) in estrogen metabolism pathway that provides a decrease in CEquinone and corresponding increase in CE concentrations [16]. The second mechanism is the modulation of activating enzyme CYP1B1, which decreases the formation of 4-CE [16]. The third is through reduction of CE-SQ to CE, as indirectly determined in vitro [16].

While we did not hypothesize that fish and eggs would be associated with EDA, our data offer this suggestion. It is plausible that fish and eggs are associated with EDA as they may be involved with the enzyme pathway that acts upon EDAs. Heterocyclic aryl amines (HAA) produced when cooking proteins are metabolized through the same pathway as CEs (i.e. acted upon by CYP, SULT, and GST enzymes) [32] [33]. If HAAs induce this pathway, these enzymes may also act upon estrogens, which then are shunted into the catechol pathway leading to EDA formation. It is also plausible that a confounding factor other than fish and eggs is responsible for this finding. We examined in our data whether a confounding variable could explain this but did not observe data to suggest this. We also investigated whether egg and fish consumption were inversely associated with consumption of fruits and vegetables but observed no evidence of an association $(P=0.93)$. Although the shared enzymatic pathway is a potential explanation for our finding, more work would be needed to determine whether the association between EDA and fish and eggs is a chance finding.

Limitations of our study include assay variability, our homogeneous study sample (affecting generalizability to the wider population), and participant recall of dietary intake. Our blinded QC indicated a high\% CV in 3 batches (excluded from this analysis), which may be attributed to different technicians handling sample preparation. However, we are reassured by the similar mean values for the EDA ratio reported previously among average-risk women [EDA ratio of 20.51 (SD 37.01)] [8] compared to the present study [22.23 (SD 16.09)]. In terms of generalizability, because our study population consists of women in premenopause, is relatively healthy, is predominantly White, has a narrow age range, and are all members of a health plan, these results may not be generalized to the wider population. However, at the expense of generalizability, we gained high internal validity. For example, our stringent exclusion criteria related to exogenous hormone use allowed us to estimate associations between diet and an endogenous hormone biomarker; and among these healthy women, there was a relatively high proportion reporting consumption of fruit and vegetable intake which allowed for examination of associations with the EDA ratio. Lastly, a potential limitation lies in the ascertainment of dietary intake through participant recall. However, a 3-DFR generally has higher validity than a food frequency questionnaire, particularly for major food groups [34].

\section{Conclusion}

These findings suggest that vegetable intake may influence the EDA ratio. These results provide the first investigation of dietary intake in relation to this novel biomarker. While these data require replication, this preliminary report suggests a link between dietary factors and an estrogen biomarker with implications for BC risk. 


\section{Acknowledgements}

This study was supported in part by NIH grant R01CA097366, K99NR012232 and Fred Hutchinson Cancer Research Center; KWR was supported by NIH grant K99NR012232 during manuscript preparation.

\section{References}

[1] Feigelson, H. (2003) Breast Cancer: Epidemiology and Molecular Endocrinology. Hormones, Genes, and Cancer, Oxford University Press, New York, 120-138.

[2] Cavalieri, E., Frenkel, K., Liehr, J.G., Rogan, E. and Roy, D. (2000) Estrogens as Endogenous Genotoxic AgentsDNA Adducts and Mutations. Journal of the National Cancer Institute Monographs, 27, 75-93. http://dx.doi.org/10.1093/oxfordjournals.jncimonographs.a024247

[3] Cavalieri, E.L. and Rogan, E.G. (2010) Depurinating Estrogen-DNA Adducts in the Etiology and Prevention of Breast and Other Human Cancers. Future Oncology, 6, 75-91. http://dx.doi.org/10.2217/fon.09.137

[4] Cavalieri, E., Chakravarti, D., Guttenplan, J., et al. (2006) Catechol Estrogen Quinones as Initiators of Breast and Other Human Cancers: Implications for Biomarkers of Susceptibility and Cancer Prevention. Biochim Biophys Acta, 1766, 63-78.

[5] Cavalieri, E., Saeed, M., Zahid, M., et al. (2012) Mechanism of DNA Depurination by Carcinogens in Relation to Cancer Initiation. IUBMB Life, 64, 169-179.

[6] Cavalieri, E.L., Stack, D.E., Devanesan, P.D., et al. (1997) Molecular Origin of Cancer: Catechol Estrogen-3,4-Quinones as Endogenous Tumor Initiators. Proceedings of the National Academy of Sciences of the USA, 94, 10937-10942. http://dx.doi.org/10.1073/pnas.94.20.10937

[7] Gaikwad, N., Yang, L., Muti, P., et al. (2009) Urine Biomarkers of Risk in the Molecular Etiology of Breast Cancer. Breast Cancer Basic Clinical Research, 3, 1-8.

[8] Gaikwad, N.W., Yang, L., Muti, P., et al. (2008) The Molecular Etiology of Breast Cancer: Evidence from Biomarkers of Risk. International Journal of Cancer, 122, 1949-1957. http://dx.doi.org/10.1002/ijc.23329

[9] Pruthi, S., Yang, L., Sandhu, N.P., et al. (2012) Evaluation of Serum Estrogen-DNA Adducts as Potential Biomarkers for Breast Cancer Risk. The Journal of Steroid Biochemistry and Molecular Biology, 132, 73-79. http://dx.doi.org/10.1016/j.jsbmb.2012.02.002

[10] Yager, JD. (2000) Endogenous Estrogens as Carcinogens through Metabolic Activation. Journal of the National Cancer Institute Monographs, 27, 67-73. http://dx.doi.org/10.1093/oxfordjournals.jncimonographs.a024245

[11] Moon, Y.J., Wang, X. and Morris, M.E. (2006) Dietary Flavonoids: Effects on Xenobiotic and Carcinogen Metabolism. Toxicology in Vitro, 20, 187-210. http://dx.doi.org/10.1016/j.tiv.2005.06.048

[12] Seow, A., Vainio, H. and Yu, M.C. (2005) Effect of Glutathione-S-Transferase Polymorphisms on the Cancer Preventive Potential of Isothiocyanates: An Epidemiological Perspective. Mutation Research, 592, 58-67. http://dx.doi.org/10.1016/j.mrfmmm.2005.06.004

[13] Jeffery, E.H. and Stewart, K.E. (2004) Upregulation of Quinone Reductase by Glucosinolate Hydrolysis Products from Dietary Broccoli. Methods in Enzymology, 382, 457-469. http://dx.doi.org/10.1016/S0076-6879(04)82025-1

[14] Lu, F., Zahid, M., Wang, C., Saeed, M., Cavalieri, E.L. and Rogan, E.G. (2008) Resveratrol Prevents Estrogen-DNA Adduct Formation and Neoplastic Transformation in MCF-10F Cells. Cancer Prevention Research (Phila), 1, 135-145. http://dx.doi.org/10.1158/1940-6207.CAPR-08-0037

[15] Yang, L., Zahid, M., Liao, Y., et al. (2013) Reduced Formation of Depurinating Estrogen-DNA Adducts by Sulforaphane or KEAP1 Disruption in Human Mammary Epithelial MCF-10A Cells. Carcinogenesis, 34, 2587-2592. http://dx.doi.org/10.1093/carcin/bgt246

[16] Zahid, M., Saeed, M., Beseler, C., Rogan, E.G. and Cavalieri, E.L. (2011) Resveratrol and N-Acetylcysteine Block the Cancer-Initiating Step in MCF-10F Cells. Free Radical Biology \& Medicine, 50, 78-85. http://dx.doi.org/10.1016/j.freeradbiomed.2010.10.662

[17] Venugopal, D., Zahid, M., Mailander, P.C., et al. (2008) Reduction of Estrogen-Induced Transformation of Mouse Mammary Epithelial Cells by N-Acetylcysteine. The Journal of Steroid Biochemistry and Molecular Biology, 109, 22-30. http://dx.doi.org/10.1016/j.jsbmb.2007.12.003

[18] Atkinson, C., Newton, K.M., Bowles, E.J., Yong, M. and Lampe, J.W. (2008) Demographic, Anthropometric, and Lifestyle Factors and Dietary Intakes in Relation to Daidzein-Metabolizing Phenotypes among Premenopausal Women in the United States. The American Journal of Clinical Nutrition, 87, 679-687.

[19] Horner, N.K., Kristal, A.R., Prunty, J., Skor, H.E., Potter, J.D. and Lampe, J.W. (2002) Dietary Determinants of Plasma Enterolactone. Cancer Epidemiology, Biomarkers \& Prevention, 11, 121-126. 
[20] Aiyer, H.S. and Gupta, R.C. (2010) Berries and Ellagic Acid Prevent Estrogen-Induced Mammary Tumorigenesis by Modulating Enzymes of Estrogen Metabolism. Cancer Prevention Research (Phila), 3, 727-737. http://dx.doi.org/10.1158/1940-6207.CAPR-09-0260

[21] Wang, L.S. and Stoner, G.D. (2008) Anthocyanins and Their Role in Cancer Prevention. Cancer Letters, 269, $281-290$. http://dx.doi.org/10.1016/j.canlet.2008.05.020

[22] Wu, X., Beecher, G.R., Holden, J.M., Haytowitz, D.B., Gebhardt, S.E. and Prior, R.L. (2006) Concentrations of Anthocyanins in Common Foods in the United States and Estimation of Normal Consumption. Journal of Agricultural and Food Chemistry, 54, 4069-4075. http://dx.doi.org/10.1021/jf0603001

[23] Saracino, M.R. and Lampe, J.W. (2007) Phytochemical Regulation of UDP-Glucuronosyltransferases: Implications for Cancer Prevention. Nutrition and Cancer, 59, 121-141. http://dx.doi.org/10.1080/01635580701458178

[24] Bradlow, H.L., Michnovicz, J.J., Halper, M., Miller, D.G., Wong, G.Y. and Osborne, M.P. (1994) Long-Term Responses of Women to Indole-3-Carbinol or a High Fiber Diet. Cancer Epidemiology, Biomarkers \& Prevention, 3, 591595.

[25] Lu, L.J., Cree, M., Josyula, S., Nagamani, M., Grady, J.J. and Anderson, K.E. (2000) Increased Urinary Excretion of 2Hydroxyestrone But Not 16 Alpha-Hydroxyestrone in Premenopausal Women during a Soya Diet Containing Isoflavones. Cancer Research, 60, 1299-1305.

[26] Haggans, C.J., Hutchins, A.M., Olson, B.A., Thomas, W., Martini, M.C. and Slavin, J.L. (1999) Effect of Flaxseed Consumption on Urinary Estrogen Metabolites in Postmenopausal Women. Nutrition and Cancer, 33, 188-195. http://dx.doi.org/10.1207/S15327914NC330211

[27] Greenlee, H., Atkinson, C., Stanczyk, F.Z. and Lampe, J.W. (2007) A Pilot and Feasibility Study on the Effects of Naturopathic Botanical and Dietary Interventions on Sex Steroid Hormone Metabolism in Premenopausal Women. Cancer Epidemiology, Biomarkers \& Prevention, 16, 1601-1609. http://dx.doi.org/10.1158/1055-9965.EPI-06-0938

[28] Zahid, M., Gaikwad, N.W., Rogan, E.G. and Cavalieri, E.L. (2007) Inhibition of Depurinating Estrogen-DNA Adduct Formation by Natural Compounds. Chemical Research in Toxicology, 20, 1947-1953. http://dx.doi.org/10.1021/tx700269s

[29] Samuni, A.M., Chuang, E.Y., Krishna, M.C., et al. (2003) Semiquinone Radical Intermediate in Catecholic EstrogenMediated Cytotoxicity and Mutagenesis: Chemoprevention Strategies with Antioxidants. Proceedings of the National Academy of Sciences of the USA, 100, 5390-5395. http://dx.doi.org/10.1073/pnas.0930078100

[30] Bonanomi, L. and Gazzaniga, A. (1980) Toxicological, Pharmacokinetic and Metabolic Studies on Acetylcysteine. European Journal of Respiratory Diseases, Supplement, 111, 45-51.

[31] Athar, M., Back, J.H., Tang, X., et al. (2007) Resveratrol: A Review of Preclinical Studies for Human Cancer Prevention. Toxicology and Applied Pharmacology, 224, 274-283. http://dx.doi.org/10.1016/j.taap.2006.12.025

[32] Turesky, R.J. (2004) The Role of Genetic Polymorphisms in Metabolism of Carcinogenic Heterocyclic Aromatic Amines. Current Drug Metabolism, 5, 169-180. http://dx.doi.org/10.2174/1389200043489036

[33] Sugimura, T., Kawachi, T., Nagao, M., et al. (1977) Mutagenic Principle(s) in Tryptophan and Phenylalanine Pyrolysis Products. Proceedings of the Japan Academy, 53, 58-61.

[34] Yang, Y.J., Kim, M.K., Hwang, S.H., Ahn, Y., Shim, J.E. and Kim, D.H. (2010) Relative Validities of 3-Day Food Records and the Food Frequency Questionnaire. Nutrition in Clinical Practice, 4, 142-148. 